\title{
THE ADAPTATION OF ACCOUNTING DATA WITHIN INTEGRATED INFORMATICS SYSTEMS
}

\author{
Lecturer PhD Radu Bălună, University of Craiova, \\ e-mail: rbaluna@yahoo.com \\ Teacher Daniela Bălună, Traian Vuia High School of Craiova, \\ e-mail:daniela_baluna@yahoo.com
}

\begin{abstract}
The increase of the reaction speed within economic organisms may be accomplished if the entire informational subsystem becomes informational. Up to now, the automatisation of some departments from firms has offered the expected results, accelerating their activity. The necessity of integrating these already-informational departments into a common system has become acute in time and the concern of forming these integrated informational systems has been accentuated. The making of these desiderata has become concrete with the help of some integrating software for the activity of the firm, called ERP (Enterprise Resources Planning).
\end{abstract}

Keywords: decision, informational system, integrated system, ERP

JEL Codes: $M 40$

The process and activities from an organization are not accidental; they are released due to some processed information which serve some persons who take decisions, while on their basis other persons start moving to execute a series of operations. The modern management of any entity, which, generally, evolves into a changing environment, cannot be conceived without the existence of an informational system capable to offer the information necessary to the foundation of decisions.

As a matter of fact, all activities taking place within an economic entity represent the conjugated result of three intercorelated subsystems, which form, on the whole, the informational system:

- the decisional (management) subsystem which has the role of conducting and leading the activity to accomplish the targets;

- the operational (leading) subsystem, whose role is to accomplish the taken decisions and to provide data concerning the developed or developing activities;

- the informational subsystem which accomplishes the connection, in both ways, between the decisional and operational subsystems.

Adaptability is a feature which has at its basis the possibility of transmitting information about the environment very rapidly from the various components of the organism to the centre of decision and back. In the case of an economic organism the support is insured by the informational subsystem. In the case of a biological organism, no matter its size, the integration degree is maximum, and the components that form the system are dedicated, in the case of an economic organism the integration degree is smaller and the components are not always dedicated.

We consider the following definition as being sufficiently complete since it states the following: "the informational system represents the organizing and integrated assembly of methods and procedures, technical means of collecting, recording, processing, transmitting and stocking of data and information concerning the activity of the leading activity and its environment" ${ }^{\text {.1 }}$.

\footnotetext{
${ }^{1}$ Constantinescu D. And collaborators - Managementul întreprinderii, Universitaria, Craiova, 1997, p. 152.
} 
When the informational system demands the use of automatic means of processing and stocking of data, the notion of informatics system appears.

The relationship between the informational system and the informatics system is like the one from the whole to the part, an aspect emphasized in figure $\mathbf{1}$ which also shows the interdependency of systems from the level of any firm.

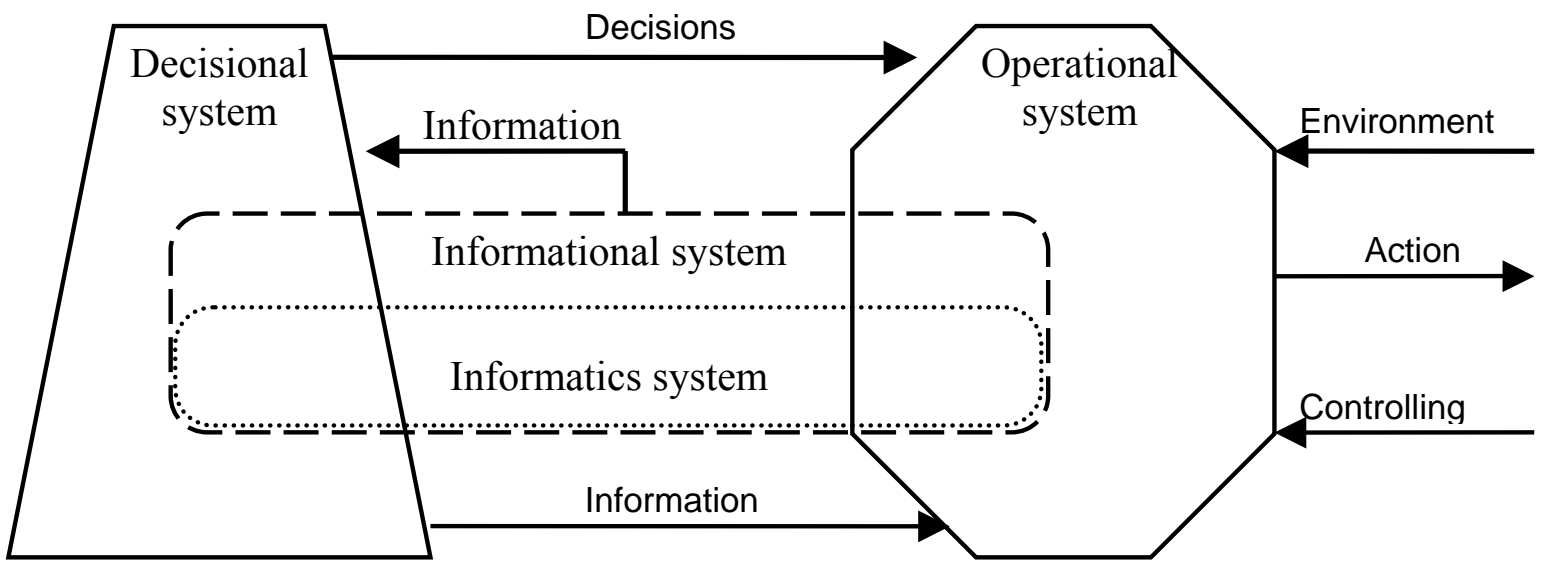

Fig. no. 1 - Interdependence of system at the level of a firm

The most general definition presents the informatics system as "a system of collecting, memorizing, processing and distributing of information which uses the electronic computer".

From the functional point of view, the informatics system includes a system of data processing presented on different memory supports, while the processing activities are embodied into procedures executed with different equipments of calculation technique, which are used in the collection and transmission of data and information.

The structure of the informatics system is suggestively presented in the following figure ${ }^{3}$ :

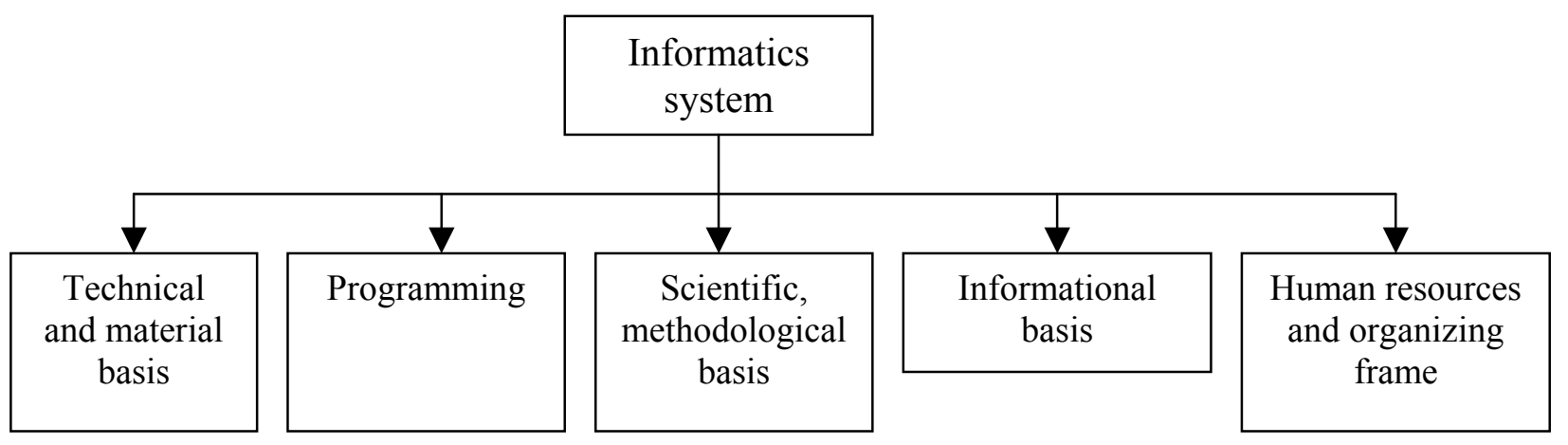

Fig. no. 2 - Structure of informatics system

The appearance of the informatics system as an essential component of the informational system of entity, as well as the necessity of automatic data processing in the economic area, are the conjugated results of several factors, of which we note:

a. the high degree of mechanization and automatisation of production processes;

b. the fast rhythm of production;

c. the necessity of the increase in the productivity of administrative work;

d. desire to obtain economic information of high quality;

\footnotetext{
${ }^{2}$ Lițoiu V. - Sisteme informatice bancare, Sitech, Craiova, 1998, p. 97.

${ }^{3}$ Sabău G.şi Lungu I. - Sisteme informatice şi baze de date, ASE, Bucharest, 1993, p. 229.
} 
e. the necessity to create integrated systems;

f. the rational use of the personnel with academic studies

The development of the automatic data processing represents a complex and long process which needs specific operations of analysis, design, programming, implementation and exploitation.

Concerning the advantages the implementation of automatic data processing in accounting may generate to the entity, we emphasize, in the following figure, those which represent at the same time improvement directions:

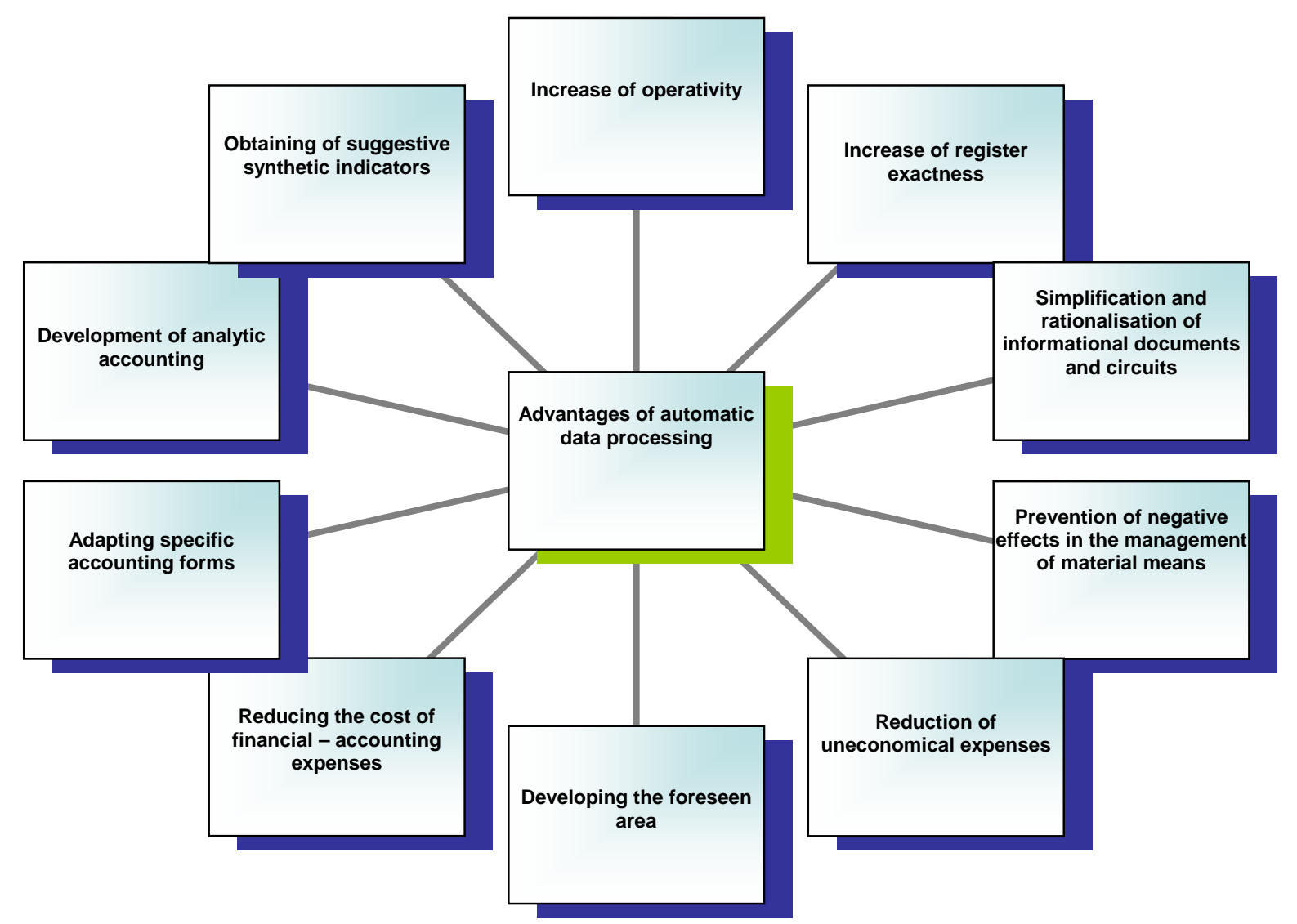

Fig. no. 3 - Advantages of implementing the automatic data processing

The conception of an informatics subsystem implies the fulfillment of at least three conditions:

- the existence of a global conception on the activities taking place in the analyzed field;

- conceiving and following a clear conception regarding the demands of the management process;

- knowing and using some methods and techniques which would allow the projection and application in informatics language of all solutions

We believe that, in order to transpose into practice, detail or at a high qualitative level, these major conditions need a laborious activity which presupposes a certain volume of work and team work.

The critical analysis of the existing informational system is the first activity in the elaboration of an informatics system and takes into consideration the following stages:

- the presentation of documents where the operations are noted;

- the description of informational flux;

- the evaluation of the informational system. 
a. The presentation of the used justifying documents needs to emphasize, for each and every, the function it fulfills, the department which makes it, its circulation into the informational system, as well as the place where it is filed.

b. The analysis of informational flux concerning the tangible assets, as an important component of the informational system of an economic unit, ensures the circuit of documents and takes into consideration the description of informational flux using flow charts with the developed activities, the involved departments, the operations and circuits of documents within each department and between them.

For example, corresponding to the nature of the most important categories of economic operations which regard the tangible assets, flow charts are elaborated concerning the informational fluxes, as it follows: for acquisition, for the moving of tangible assets within the unit, for operations regarding the tangible assets lent to other units, for rented tangible assets, for cashing operations of tangible assets, for the selling of tangible assets.

c. From the critical analysis of the existing informational system, some limits can be observed, which, in our opinion, negatively influence the decisions adopted by the unit:

c1. deficiency of information: lack of information from the system; needless information;

c2. inadequate means:

- documents: too large volume; un-typed or inadequate for PAD; inadequate flows of circulation or processing; lack of stipulated documents;

- technical means: weak concern for equipment; the use in reduce technical capacity; inadequate maintenance; inadequate operation system; nonperforming applicative programs;

- personnel: too many in certain departments; too low in some departments; weak concern for selecting and promoting; lack of training concerns;

c3. too high functioning costs.

The increase of reaction speed for the economic organisms may be accomplished only if the entire informational subsystem is automatized. Therefore, the finding of some cheap and accessible solutions has been tried for some time in order to automate all components forming it. Until a few years ago, the automatisation of some departments from firms reached the goals, accelerating them and making them efficient. The necessity of integrating these already-informational departments into a common system has become acute in time and the concern of forming these integrated informational systems has been accentuated. Their forming is possible with the help of some integrating software for the activity of the firm. This category of software is called ERP (Enterprise Resources Planning).

Today there are many similar programs with slightly different functioning, of which we note those accomplished in the international environment.

\section{Commercial packets:}

- Enterprise Business System, produced by Made2Manage Systems;

- Epicor Enterprise, produced by Epicor;

- Macola ERP, produced by Exact Software;

- MFG/PRO, produced by QAD;

- Microsoft Dynamics, produced by Microsoft Business Division;

- NetERP, produced by NetSuite Inc.;

- Oracle e-Business Suite, produced by Oracle etc.

II. Free of charge packets:
$>$ Compiere
- made by ComPiere Inc.;
$>$ Tiny ERP - made by Tiny sprl;
$>$ ERP5
- made by Nexedi;
$>$ GNUe
- made under license GNU. 
In Romania, the accomplishment of this type of packets takes place slower since this concept (ERP) appeared later. A positive example is "Socrate +", made by Bit Software.

The forming of a single program which is necessary not only to the finance-accounting personnel but also to those from human resources and supply represents a priority for any firm. Each of these departments usually has its own informatics system, according to the purpose of the department. An ERP combines them into one system which uses one data basis which can be accessed by any of the departments and through which they can distribute information.

An ERP replaces all those informational systems related to departments with one modular one. Each department has its own necessary software provided by a module of ERP only that these modules are integrated and can communicate.

In the 90's the first ERP systems were developed but they were like a monolith. They could be bought only integrally, with all modules, no matter the firm needed them or not. Later on, this drawback had been eliminated through the realization of ERP systems which can be purchased on modules, without buying the entire packet. This fact became an advantage, since the integration of an ERP in a firm is neither an easy nor a cheap process. Thus, a firm may plan the way it purchases the ERP on modules, and also the order its departments will be integrated in this system.

The Enterprise Resource Planning (ERP) systems are systems of management of information, which integrate and automate a big part of the activities taking place in an enterprise. ERP software is an integrated one, including all the functional departments of the firm.

The concept of enterprise resource planning derives from that regarding the manufacturing resource planning MRP II, which, in its term, appeared from the updating of the initial concept of material requirements planning MRP.

An ERP system usually allows the integration of the following components: production, logistics, distribution, inventory, transport, accounting, etc. The ERP software helps at the controlling and automating of many activities, such as: sales, delivery, invoicing, management of quality, management of human resources, etc.

The ERP is usually named back office system, thus emphasizing the fact that it doesn't directly involve the partners' participation (suppliers and customers). Thus, it is in contrast with the concept of system front office as the customer relationship management-CRM which works directly with the customers, or the e-business systems such as e-commerce, e-governing, e-telecom and e-finances, or the system of supplier relationship management-SRM.

Because of the very complex objectives of such a software packet, this comprises a large volume of program lines and its implementation, at the level of a firm, involves an entire army of analysts, programmers and users. This happened before the appearance and development of internet. The internet allowed developers access to the computers of a firm to install the latest corrections or standard updates.

The implementation of an ERP without the help of some specialists may be a very expensive project for the big companies, especially for the transnational ones. The firms specialized in ERP implementations may cover the process of accomplishment-implementation in a slower time (approximately 6 months, in some opinions), comprising the testing of the pilot software.

The ERP system is generally bound to the software for the supply chain management SCM and to the automatisation systems of logistics. The software for the supply chain management may extend the functioning of an ERP system to include other connections with suppliers.

To implement an ERP system, the firms seek the help of those who commercialize such systems, but also the assistance of some consulting companies for this area. The consulting for the implementation of an ERP system implies two levels, that is: business consultancy and technical consultancy.

For the consultancy from the first level the consulting firm studies the current activities of the entity which requests the implementation of the ERP system in the attempt of accomplishing the correspondence between the processes rolled by it and those included into an ERP system. Thus, the 
configuration of the ERP system is insured at the level of functional modules, according to the entity's needs.

The technical consultancy involves programming activities through which the adapting of the ERP system's modules at the firm's features is tried. The firms which commercialize ERP systems usually take care of the modification of their software to meet the customers' needs.

Today ERP systems based on the web interface can be met. The firms are interested by such systems since they do not need the installing of client applications, only the server application which can be maintained centralized, and it is also possible to install it in a large variety of operating systems. As long as there is an internet connexion, the ERP system can be accessed from anywhere with the help of a single browser.

From the specialized practice and literature, three ERP implementing strategies can be distinguished at the level of a firm, and these are: the Big Bang, franchising, slam-dunk.

a. The first strategy, the Big Bang, is the most ambitious and difficult of all implementing strategies. The firms try to implement the ERP simultaneously in all departments. This variant has been used especially during the first implementations, a fact favored by the problem of the 2000's bug for old systems, when all the firm's departments had to change the software. The special problems met at the implementation of the ERP, especially at the end of the 90s, represented an alarm concerning the use of this strategy. To try to convince all employees to cooperate and to accept the new software system at the same time, needs an extraordinary effort, generated by the fact that no one will be on the side of the new system implementation, even for the fact that it isn't known sufficiently well. The ERP systems inevitably need compromises. Many departments already have their own department systems, which are well known and have proved, at least up to a point, that they function. In most cases, the ERP systems offer neither functionality nor the comfort and familiarization the old system used to offer, the change being hard to accept. In many cases, the speed of the new system may be altered by the fact that it serves the entire firm and not only one department.

b. The strategy named franchising may be applied to a diversity of firms, which do not have the same processes in each unit (branch). More ERP systems may be installed in this case, independent at the level of each unit, which make the connection between them only for those common processes, as the financial - accounting transactions. It's the most often implementation strategy. In most cases, the units have separate instances of the same ERP, practically a separate data base of rigorously bound data. The system connects all the information that need to be separated in order to obtain performances at the level of the firm, not only at the level of a unit or only for the processes which do not differ too much from one unit to another. These implementations usually start with a demonstration or with a pilot installing in a unit which functions well and where there is a personnel opened for change and patient, where events which would generate problems do not appear. Once the implementing team installs a part of the system and corrects all errors the sale of the other modules starts using the first implementation as reference of well functioning very persuasive for the client. The planning of this strategy needs a long time. Many of the companies which installed an ERP through franchising are very tempted to use at the other units the Big Bang strategy or even for the rest of the firm.

c. Slam dunk represents the strategy through which only some processes are integrated, the most important ones, such as, for example, the financial ones. This strategy is used for small firms, which expect to develop. Its purpose is that of installing a fast ERP and of obtaining functionality in the first place. The firms which chose this variant sustained that the result is special. Most of them use the ERP system as a developing infrastructure. Yet, many discovered that this ERP implementation strategy is better than the bound system, since it does not force the employees to change their own habits. Actually, accomplishing the difficult work to replace the processes, as the system asks, competition and productivity are stimulated, since those who have accomplished this work will feel the benefits brought by the new software. 
Taking into consideration the lack of an ERP system, a manufacturer may find himself in the situation of having more software applications which do not communicate among them. An ERP may offer answers at any moment regarding the questions, such as:

a. Which is the best option to make an investment starting from the necessary components supplied by different companies, which are always changing?

b. How could you follow the status of the investment from the moment of its appearance till finalization and payment, managing the interdependences of a complex necessary of components for a product in the real dynamic world?

c. How can you predict exactly the date it will be finalized at?

d. How can there be verification between what was stipulated and what was accomplished?

e. How the above-mentioned can be accounted, and how can the costs and final reception be monitored?

An ERP includes elements concerning the computers' security to prevent, on the one side, the intrusions from outside the firm, as the industrial espionage and, on the other side, those from the interior, as dilapidation and sabotage. The prevention is integrated part in the construction of an ERP.

Many of the problems firms have with an ERP system are generated by inadequate investment in the continuous training for all personnel including for those that take care of the implementation and testing of modifications, but also the lack of integrated politics which affect the way data from the ERP system are used and maintained in accordance to reality.

The functioning in good conditions of an ERP needs at least the effort of all departments to update the data existing in the system.

People don't like to change, but an ERP system determines them to change the way they do their work. Therefore, the value of an ERP system is difficult to define. The software is less important than the changes firms make concerning the way they run their business. If an ERP is used to improve the way employees do their job, then its value will be understood. If the software is installed, without trying to improve the way employees do their job, no change will be observed. Also, it is possible for the new software to slow down the rhythm of work for all employees, compared to the rhythm reached with the old software, because of lack of familiarization with it.

The limitations and traps of an ERP include:

- dependency of abilities, experience of labor force and the training level concerning the way the system functions correctly. Many firms reduce the costs with users' training. The private small companies are many times decapitalised, meaning that many times their ERP system is used by personnel with unsatisfactory training;

- the personnel fluctuations - the firms may hire new managers with corresponding training for the use of an ERP and who can propose changes regarding the activities taking place inside the firm, which are not in accordance with the synchronizing of ERP;

- the installing of ERP may be very expensive;

- the distributors of ERP systems may annually ask for sum of money to renew the using license, which are not in accordance with the firm dimension which uses the ERP or with its profitability;

- the technical support personnel offers solutions, which, usually, do not match the structure of the firm. Problems of information security may appear, if, for example, an employee without computer programming knowledge is explained how to change a data base on the way, for a firm which needs the auditing of the changes to be in accordance with some norms;

- the ERP systems are many times considered too rigid and difficult to adapt at the flux specific to a firm - this represents one of the most important failure causes;

- the ERP may be difficult to use;

- the system may suffer from the dependency between departments and it is possible for an inefficient department to influence the efficiency of the other departments; 
- many of the connections with other applications need a high precision for an efficient functioning. A firm may reach the desired efficiency level and, in time, because of the accumulation of data which are not in accordance with reality, it may lose it;

- once an ERP is implemented, the costs of its change are too high for any partner (they reduce flexibility and strategic control at the level of firm);

- the unclear delimitation of the firm's limits may cause problems to accounting, responsibility lines and the employees' morals;

- the limiting of intern information transmission, sensible among departments may reduce the software efficiency;

- there are frequent problems concerning the consistency with the ERP systems of the partners.

All these possible drawbacks may be avoided if they are correctly managed, that is if they are taken into consideration and carefully treated once the implementation of the integrated system takes place.

\section{References}

1. Constantinescu D. and collaborators - Managementul întreprinderii (Management of Enterprise), Universitaria, Craiova, 2007, p. 152.

2. Lițoiu V. - Sisteme informatice bancare (Banking Informatics Systems), Sitech, Craiova, 1998, p. 97.

3. Sabău G., Lungu I. - Sisteme informatice şi baze de date (Informatics Systems and Data Base), ASE, Bucharest, 2003, p. 229. 